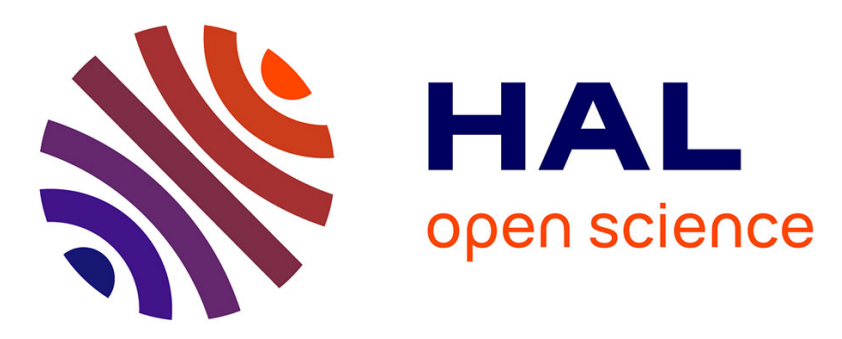

\title{
Hypersaline microbial fuel cell equipped with an oxygen-reducing microbial cathode
}

Mickaël Rimboud, Luc Etcheverry, mohamed Barakat, Wafa Achouak, Alain Bergel, Marie-Line Délia

\section{- To cite this version:}

Mickaël Rimboud, Luc Etcheverry, mohamed Barakat, Wafa Achouak, Alain Bergel, et al.. Hypersaline microbial fuel cell equipped with an oxygen-reducing microbial cathode. Bioresource Technology, 2021, 337, pp.125448. 10.1016/j.biortech.2021.125448 . hal-03295885

\section{HAL Id: hal-03295885 \\ https://hal.science/hal-03295885}

Submitted on 22 Jul 2021

HAL is a multi-disciplinary open access archive for the deposit and dissemination of scientific research documents, whether they are published or not. The documents may come from teaching and research institutions in France or abroad, or from public or private research centers.
L'archive ouverte pluridisciplinaire HAL, est destinée au dépôt et à la diffusion de documents scientifiques de niveau recherche, publiés ou non, émanant des établissements d'enseignement et de recherche français ou étrangers, des laboratoires publics ou privés. 


\section{OATAO \\ Open Archive Toulouse Archive Ouverte}

\section{Open Archive Toulouse Archive Ouverte}

OATAO is an open access repository that collects the work of Toulouse researchers and makes it freely available over the web where possible

This is an author's version published in: http://oatao.univ-toulouse.fr/ 28126

Official URL : https://doi.org/10.1016/j.biortech.2021.125448

\section{To cite this version:}

Rimboud, Mickä̈l $\fallingdotseq$ and Etcheverry, Luc $\bullet$ and Barakat, Mohamed and Achouak, Wafa and Bergel, Alain equipped with an oxygen-reducing microbial cathode. (2021) Bioresource Technology, 337 (125448). ISSN 0960-8524

Any correspondence concerning this service should be sent to the repository administrator: tech-oatao@listes-diff.inp-toulouse.fr 


\title{
Hypersaline microbial fuel cell equipped with an oxygen-reducing microbial cathode
}

\author{
Mickaël Rimboud $^{\mathrm{a}}$, Luc Etcheverry ${ }^{\mathrm{a}}$, Mohamed Barakat ${ }^{\mathrm{b}}$, Wafa Achouak ${ }^{\mathrm{b}}$, Alain Bergel ${ }^{\mathrm{a}}$, \\ Marie-Line Délia ${ }^{a, *}$ \\ ${ }^{a}$ Laboratoire de Génie Chimique, Université de Toulouse, CNRS, INPT, UPS, 4 Allée Emile Monso, 31432 Toulouse, France \\ ${ }^{\mathrm{b}}$ Lab of Microbial Ecology of the Rhizosphere (LEMIRE), BIAM, UMR 7265, CEA-CNRS-Aix Marseille University, CEA Cadarache, 13108 Saint Paul Lez Durance, \\ France
}

\section{H I G H L I G H T S}

- MFCs were implemented in hypersaline medium with $\mathrm{O}_{2}$-reducing microbial cathodes.

- Stable power density of $209 \pm 24 \mathrm{~mW} \mathrm{~m}^{-2}$ was produced over a week.

- Efficiency of the microbial cathode was linked to a redox system centred at $0.2 \mathrm{~V} / \mathrm{SCE}$.

- Cathodes were dominated by Gammaproteobacteria (Alteromonadales, Oceanospirillales).

- An unclassified order linked to the genus Thioalobacter may be essential.

\section{A R T I C L E I N F O}

Keywords:

Biocathode

Salt marsh sediment

Bioelectrochemical system

Desulfuromonas

Thioalobacter

\begin{abstract}
A B S T R A C T
Microbial anodes and oxygen reducing microbial cathodes were designed separately under constant polarization at $+0.1 \mathrm{~V} / \mathrm{SCE}$ in a hypersaline medium $(\mathrm{NaCl} 45 \mathrm{~g} / \mathrm{L})$. They were then associated to design two-compartment microbial fuel cells (MFCs). These MFCs produced up to $209 \pm 24 \mathrm{~mW} \mathrm{~m}^{-2}$ during a week. This was the first demonstration that hypersaline MFCs equipped with microbial cathodes can produce power density at this level. Desulfuromonas $s p$. were confirmed to be key species of the anodes. The efficiency of the cathodes was linked to the development of a redox system centred at $+0.2 \mathrm{~V} / \mathrm{SCE}$ and to the presence of Gammaproteobacteria (Alteromonadales and Oceanospirillales), especially an unclassified order phylogenetically linked to the genus Thioalobacter. Comparing the different performance of the four MFCs with the population analyses suggested that polarization at $+0.1 \mathrm{~V} / \mathrm{SCE}$ should be maintained longer to promote the growth of Thioalobacter on the cathode and thus increase the MFC performance.
\end{abstract}

\section{Introduction}

Microbial fuel cells (MFCs) have shown impressive progress in the last ten years (Santoro et al., 2017) but the power density produced remains much too low to consider large size extrapolation of the technology. A major issue, among others, is the high internal resistance of the cells due to the low ionic conductivity of usual electrolytes (Oliot et al., 2016b). The ionic conductivity ( $\sigma$ ) of common electrolytes used in MFCs is often around $1 \mathrm{~S} \mathrm{~m}^{-1}$ for synthetic media, and it can even be much lower when wastewater is used (Oliot et al., 2016b). It can easily be shown that such low ionic conductivities severely hinder MFC performance. The ohmic loss $(\Delta U)$ due to the ionic transport between an anode and a cathode facing each other and separated by a distance $l$ is:

$\Delta U=\frac{l}{\sigma} J$

where $J$ is the current density. This equation indicates, for example, that a current of $50 \mathrm{~A} \mathrm{~m}^{-2}$ flowing between an anode and a cathode $1 \mathrm{~cm}$ apart is opposed by an ohmic drop of $0.5 \mathrm{~V}$ in a medium of $1 \mathrm{~S} \mathrm{~m}^{-1}$ conductivity. This ohmic drop would be of the same order of magnitude as the maximum cell voltage that most MFCs can produce. The low conductivity of common MFC electrolytes precludes the generation of

\footnotetext{
* Corresponding author.

E-mail address: alain.bergel@toulouse-inp.fr (M.-L. Délia).
} 
high current density. Increasing the electrolyte conductivity is a prerequisite if the objective is to increase the power density MFCs can produce and thus to progress towards economically-efficient devices.

Saline $(0$ to $1 \% \mathrm{w} / \mathrm{v})$ to hypersaline (greater than $3.5 \% \mathrm{w} / \mathrm{v})$ electrolytes may be seen as a promising solution (Nam and Logan, 2011; Grattieri et al., 2017b). Hypersaline media can reach ionic conductivities above $10 \mathrm{~S} . \mathrm{m}^{-1}$, which results in a proportional decrease in the ohmic drop inside the MFC (equation (1)). A few studies have started to report interesting results with saline and hypersaline MFCs (Grattieri and Minteer, 2018). Abrevaya et al. succeeded in producing power

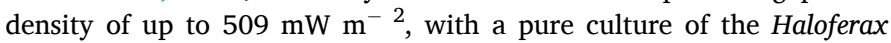
volcanii archea, working in a medium of ionic strength around $2.7 \mathrm{M}$ (Abrevaya et al., 2011). A power density of $390 \mathrm{~mW} \mathrm{~m}^{-2}$ was produced with an MFC used to treat seafood wastewater. Actually, no data was provided about the salinity, but it can be assumed to be high given the nature of the inoculum (Sun, 2012). More recently, 504 and $572 \mathrm{~mW}$ $\mathrm{m}^{-2}$ were reached using MFCs inoculated with rice paddy-field soil

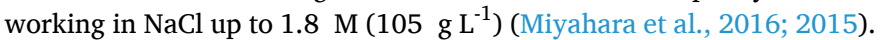
Nevertheless, the power density produced by even these most efficient hypersaline MFCs remains limited and most other hypersaline MFCs have produced much lower power densities, generally of only a few tens of $\mathrm{mW} \mathrm{m}^{-2}$ (Grattieri et al., 2017a; 2017b; Robertson et al., 2019).

Another rate-limiting step is the cause of the low efficiency of hypersaline MFCs: the slow kinetics of the oxygen-reducing cathodes. This step is known to be rate-limiting for all MFCs (Liew et al., 2014; Wei et al., 2011) and it seems to be even more acute for hypersaline MFCs. Several microbial anodes have produced remarkably high current density in hypersaline media (Rousseau et al., 2013; 2015). Such anodes can show their full potential when combined with other cathodes than oxygen-reducing ones. A hypersaline microbial electrolysis cell (MEC) has thus worked with stable current above 50 A.m ${ }^{-2}$ for weeks (Rousseau et al., 2020). In this case, the cathode ensured hydrogen evolution instead of oxygen reduction. It is therefore essential to concentrate efforts on the design of hypersaline oxygen-reducing cathodes.

Almost all hypersaline MFCs reported so far have been equipped with abiotic oxygen-reducing (OR) cathodes. Unfortunately, metallic and organic catalysts for oxygen reduction show poor efficiency at the nearneutral $\mathrm{pH}$ values that are required in MFCs. Moreover, to be effective, metallic and organic catalysts require clean electrolyte. In the media used for MFCs, fast fouling and biofouling of the surface of abiotic cathodes severely inhibit their performance (Oliot et al., 2016a; Pasternak et al., 2016).

Microbial cathodes for oxygen reduction may offer worthwhile alternatives, because of their low cost and their capacity to work at neutral pH (Erable et al., 2012). Microbial cathodes can also take advantage of biofilm development on their surface. For instance, it has been observed that Pt-free OR cathodes perform similarly to Pt-loaded cathodes after a few weeks of operation because of the development of an aerobic biofilm on their surface (Santoro et al., 2012). Notable successes have been reported with MFCs equipped with OR microbial cathodes, with power densities of $554 \mathrm{~mW} \mathrm{~m}^{-2}$ being produced (Xia et al., 2013) and up to 620 $\mathrm{mW} \mathrm{m}^{-2}$ (Milner et al., 2016; Milner and Yu, 2018) or even $679 \mathrm{~mW} \mathrm{~m}^{-2}$ with a plant-MFC (Wetser et al., 2015). Finally, one of the greatest advantages of microbial OR cathodes is the room for progress that can be expected (Liew et al., 2014). We are still in the infancy of their engineering development (Huang et al., 2011) and making headway in deciphering their mechanisms may open avenues for considerable improvement. In particular, OR microbial cathodes often have complex microbial populations and we can hope to improve them by identifying the most active species for oxygen reduction and promoting their development.

To the best of our knowledge, only one study has designed a hypersaline MFC (electrolyte containing 62-65 g/L NaCl) equipped with an OR microbial cathode (Roustazadeh Sheikhyousefi et al., 2017). Power density remained pretty low, with a maximum of $65 \mathrm{~mW} \mathrm{~m}^{-2}$ when the MFC was fed with acetate (the chemical oxygen demand corresponded to $15.6 \mathrm{mM}$ acetate). Nevertheless, the authors suggested that the performance may have been limited by the bioanode because anaerobiosis was not ensured in the anode compartment.

The purpose of the present work is to advance in the development of hypersaline MFC equipped with an OR microbial cathode. Several studies have reported powerful bioanodes formed from salt marsh sediment (Rousseau et al., 2013; 2015). The bioanodes were formed under constant polarization at $+0.1 \mathrm{~V} / \mathrm{SCE}$. The highest current densities, up to $85 \mathrm{~A} \mathrm{~m}^{-2}$, were obtained with media containing $45 \mathrm{~g} / \mathrm{L}$ $\mathrm{NaCl}$. These bioanodes have been implemented for weeks in a microbial electrolysis cell for the production of hydrogen (Rousseau et al., 2020).

Recently, the same salt marsh sediment has shown the capacity to form efficient OR microbial cathodes under polarization at $+0.1 \mathrm{~V} /$ SCE and a constant supply of air (Rimboud et al., 2021). These biocathodes produced up to $-2.2 \mathrm{~A} \mathrm{~m}^{-2}$ during voltammetric experiments.

In both contexts, bioanodes and biocathodes were designed in the same type of electrolyte, which was derived from a Starkey medium and complemented with $45 \mathrm{~g} / \mathrm{L} \mathrm{NaCl}$, having a conductivity of $10.4 \mathrm{~S} \mathrm{~m}^{-1}$. They were formed under controlled polarization at the same potential value of $+0.1 \mathrm{~V} / \mathrm{SCE}$. All these previous investigations were performed in 3-electrode analytical set-ups, and these bioanodes and biocathodes have not yet been coupled together in an MFC.

The purpose of the present work was to design a hypersaline MFC by associating a bioanode and an OR biocathode, both formed from salt marsh sediment using the previously described methodologies. Accordingly, in the first phase, the bioanodes and biocathodes were formed separately under polarization at $+0.1 \mathrm{~V} / \mathrm{SCE}$. Bioanodes and OR biocathodes were then associated in double-compartment MFCs. During both polarization and MFC operation, the bioanodes were fed with sodium acetate as electron source and the OR biocathodes were constantly supplied with air.

MFCs were continuously operated with a load of $1200 \Omega$ and they were characterized every three days by power and polarization curves. The bacterial population of the anodic and cathodic biofilms were analysed after pyrosequencing of the DNA coding the 16S rRNA and compared with the microbial compositions available in the literature for similar bioanodes and OR biocathodes formed under controlled polarization in 3-electrode set-ups.

\section{Materials and methods}

\subsection{Medium and inoculum}

Salt marsh sediment was collected from salt marshes near the Mediterranean Sea (Salins de Saint Martin, Gruissan, France). Sediment was kept at room temperature in a $50 \mathrm{~L}$ closed container and used fresh during the two weeks following sampling to avoid long-term anaerobic evolution that might alter the bacterial composition.

The medium used was derived from the Starkey medium and consisted of $0.5 \mathrm{~g} \mathrm{~L}^{-1} \mathrm{~K}_{2} \mathrm{HPO}_{4}, 1 \mathrm{~g} \mathrm{~L}^{-1} \mathrm{NH}_{4} \mathrm{Cl}, 1 \mathrm{~g} \mathrm{~L}^{-1} \mathrm{Na}_{2} \mathrm{SO}_{4}, 0.1 \mathrm{~g} \mathrm{~L}^{-1}$ $\mathrm{CaCl}_{2} \cdot 2 \mathrm{H}_{2} \mathrm{O}, 2 \mathrm{~g} \mathrm{~L}^{-1} \mathrm{MgSO}_{4} \cdot 7 \mathrm{H}_{2} \mathrm{O}, 45 \mathrm{~g} \mathrm{~L}^{-1} \mathrm{NaCl}$. Both bioanodes and OR biocathodes were formed using the same mineral medium inoculated at $10 \% \mathrm{v} / \mathrm{v}$ with salt marsh sediment. The $\mathrm{pH}$ was fixed at 7.0 in all reactors at the beginning of experiments.

\subsection{Formation of the microbial electrodes (bioanodes and $O R$ biocathodes)}

Four bioanodes and four OR biocathodes were formed separately under polarization at $+0.1 \mathrm{~V} / \mathrm{SCE}$ using three-electrode set-ups. Each bioanode and OR biocathode was individually formed in a separate cell. The future bioanode or biocathode was the working electrode and was made of $0.5 \mathrm{~cm}$ thick carbon felt (Mersen, France). The bioanodes consisted of a rectangular piece of carbon felt of $12 \mathrm{~cm}^{2}$ $(4 \mathrm{~cm} \times 3 \mathrm{~cm}$ ); the biocathodes consisted of a circular piece of carbon felt $4 \mathrm{~cm}$ in diameter (around $12.5 \mathrm{~cm}^{2}$ ). The bioanodes or biocathodes 
were connected using a titanium wire $1 \mathrm{~mm}$ in diameter (Alfa Aesar, Germany), where the part in contact with the solution was insulated with a heat-shrinkable sheath. The counter electrodes were $12 \mathrm{~cm}^{2}$ platinum grids connected with platinum wires and the reference electrodes were saturated calomel electrodes (SCE, $\mathrm{E}=+0.240 \mathrm{~V} / \mathrm{SHE}$ ).

The bioanodes were directly designed in situ in the sealed container destined to form the anodic compartment of the future MFCs (see MFC design below), which contained $800 \mathrm{~mL}$ of inoculated medium. The medium was firstly deoxygenated by 30 min' nitrogen sparging and thereafter fed with sodium acetate $(40 \mathrm{mM})$. The concentration of sodium acetate was monitored throughout the experiment, during both the polarization and the MFC phases. It remained between 15 and $40 \mathrm{mM}$.

The OR biocathodes were designed in reactors derived from Schott bottles containing $600 \mathrm{~mL}$ of inoculated medium. The medium was under permanent forced aeration via aquarium pumps during the whole polarization phase. All the polarization phases were performed in an oven at $30^{\circ} \mathrm{C}$.

Cyclic voltammetry was performed at the beginning and the end of the 12-day polarization phase. The potential scan started at the open circuit potential, down to $-0.6 \mathrm{~V} / \mathrm{SCE}$ and up to +0.2 (bioanodes) or $+0.5 \mathrm{~V} / \mathrm{SCE}$ (biocathodes). Polarization phases (chronoamperometry) and cyclic voltammetries were performed with a multichannel potentiostat (VMP3, Biologic, France) equipped with the EC-Lab software.

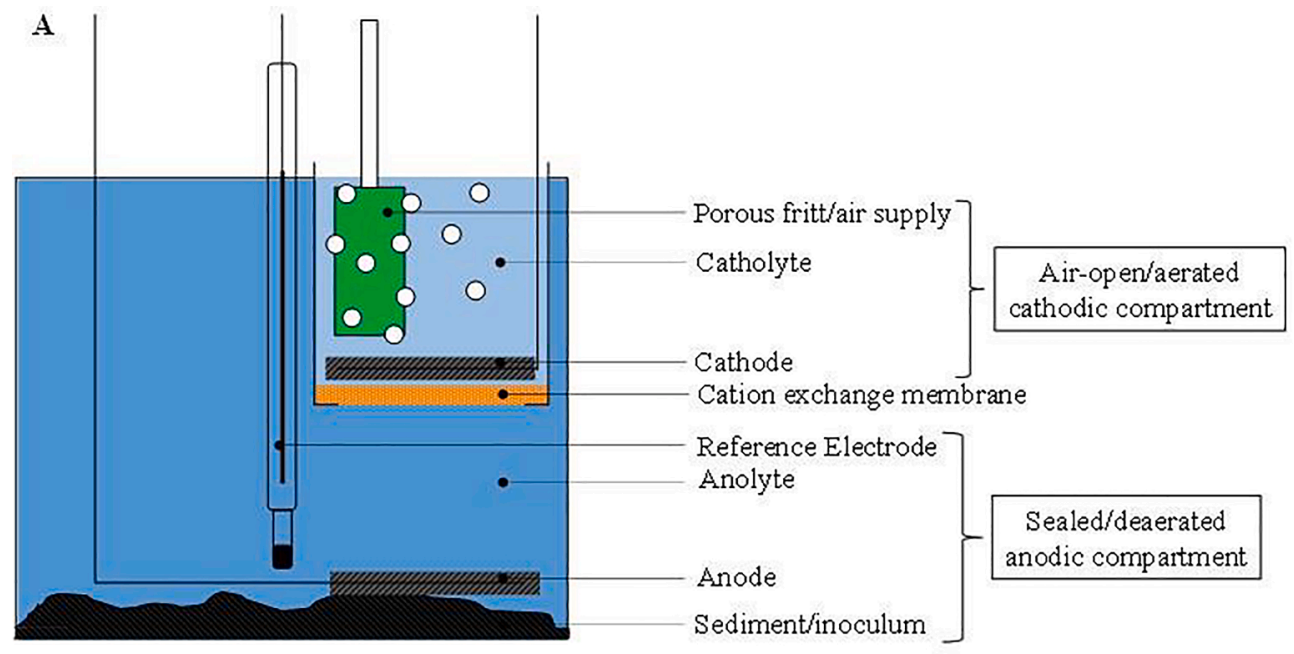

B
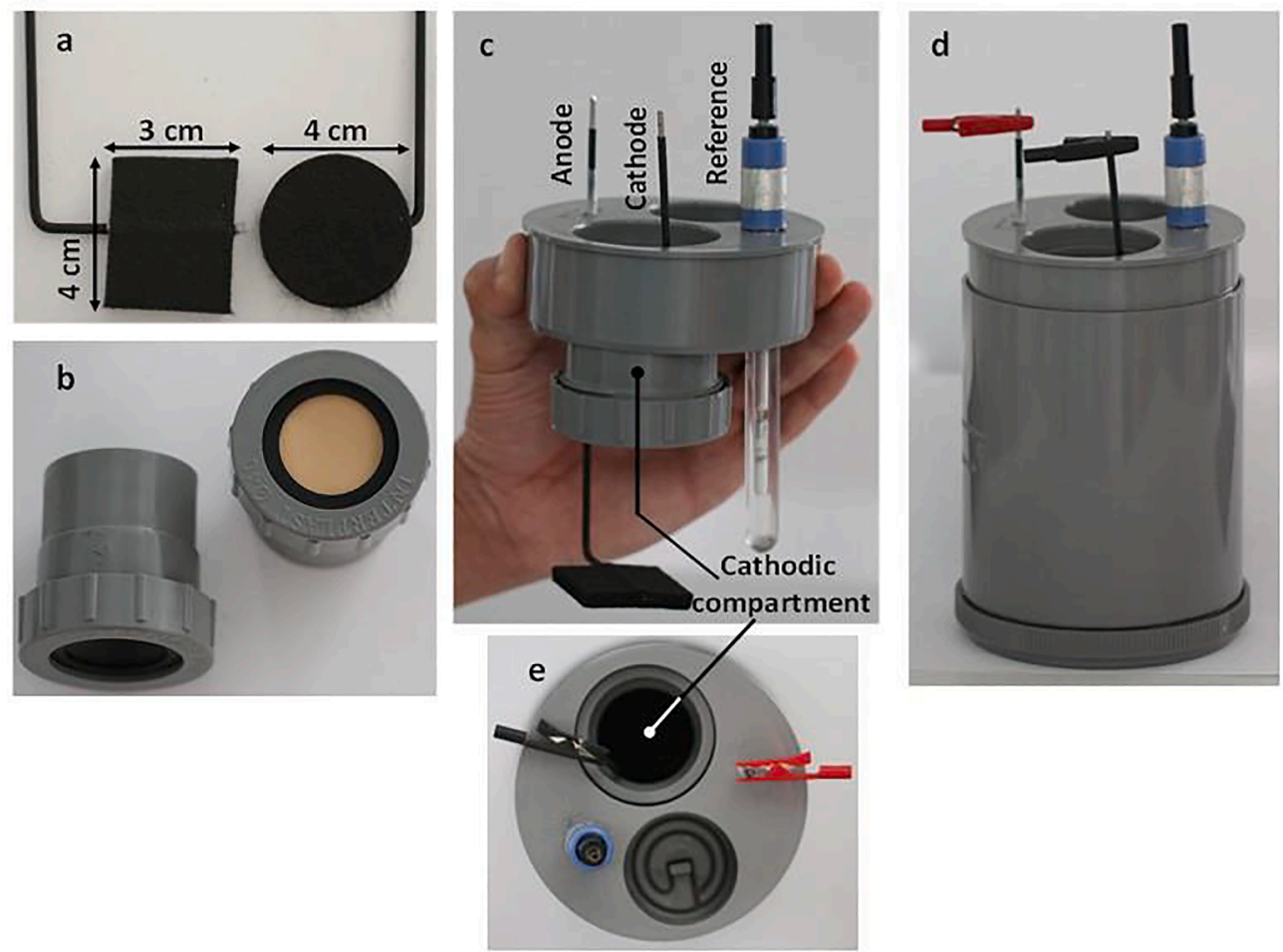

Fig. 1. (A) Scheme of the microbial fuel cell set-up. (B) Pictures of the MFC set-up a: carbon felt anode (rectangular) and cathode (circular); b: Cathodic compartment, with the CMI 7000 membrane at the bottom; c: upper part of the MFC, supporting the three-electrode set-up and the cathodic compartment; d: photo of whole MFC, lateral view; e: whole MFC, top view. 


\subsection{Microbial fuel cell design}

The microbial fuel cells were made from a sealed PVC container with an adapted cathodic compartment open to the air as described in Fig. 1A. Pictures of the device and its components are presented in Fig. 1B.

The PVC container was a cylinder $11 \mathrm{~cm}$ in diameter and $13 \mathrm{~cm}$ high, which contained $800 \mathrm{~mL}$ of medium. The air-open, cathodic compartment consisted of a PVC tube $4 \mathrm{~cm}$ in diameter and $7 \mathrm{~cm}$ high. Anodic and cathodic compartments were separated by a cation exchange membrane CMI 7000, $4 \mathrm{~cm}$ in diameter. The OR biocathode was placed immediately on the upper side of the membrane and the anode near the bottom of the fuel cell, partly imbedded in the salt marsh sediment used as inoculum. The anode was aligned with the membrane and the OR biocathode. The distance between the two electrodes was in the 6-7 cm range.

At the end of the 12-day polarization phase, the OR biocathodes were taken from their reactors and inserted in the cathodic compartments of the microbial fuel cells, where the bioanodes had already been formed. The best-performing bioanode was associated with the best-performing OR biocathode to design MFC1. The second best-performing electrodes were associated to design MFC2, and so on, in decreasing order of performance, for MFC3 and MFC4. The cathodic compartment was filled with a portion of the medium from the reactors where the biocathodes had been designed.

\subsection{MFC operation and characterization}

The MFCs were connected to a resistance of $1200 \Omega$ and the evolution of the voltage with time was recorded using the VMP3 multichannel potentiostat. During MFC operation, oxygen was supplied to the cathodic compartment using aquarium pumps. Evaporation of the catholyte occurred due to the small volume of the cathodic compartment and the forced aeration. The loss was compensated by addition of distilled water mixed with Starkey medium from the polarization reactors. Concentration of sodium acetate in the anolyte was monitored during the whole MFC operation and maintained between 15 and $40 \mathrm{mM}$.

MFCs were characterized by their polarization and power curves, which were determined with a range of external resistances from $10 \Omega$ to $150 \mathrm{k} \Omega(10,33,100,330,1000,3300,10000,18000,33000$, 100000 and $150000 \Omega$ ). For each resistance, the voltage between the two electrodes and the potential of the OR biocathodes versus the SCE were recorded using two high-input-impedance multimeters (IDM93M, RS Components SAS, France) after $15 \mathrm{~min}$ of stabilization. The first power curves were recorded immediately after the implementation of the OR biocathodes. Successive characterizations were then performed every $72 \mathrm{~h}$ thereafter. Power curves were recorded at room temperature, whereas MFCs were kept in the oven $\left(30^{\circ} \mathrm{C}\right)$ during operation. The current density values were calculated in relation to the cathode surface area $\left(12.5 \mathrm{~cm}^{2}\right)$.

\subsection{Population analyses}

Biofilms were stripped from the surface of the electrodes and resuspended in $15 \mathrm{~mL}$ of PBS by ultrasonication $(15 \mathrm{~min}$ at $80 \mathrm{~W}$, Fisher Scientific FB 15061). The biofilm suspensions were centrifuged and the solid material was collected. DNA extraction was performed using the DNeasy PowerBiofilm extraction kit from Qiagen (Netherlands). The DNA samples were sent to the Research and Testing Laboratory (RTLab - Lubbok, Texas, USA) for 454 pyrosequencing (Roche) using 28F (5'-GAG TTT GAT YMT GGC TC-3') and 519R (5'GWA TTA CCG CGG CKG CTG-3') primers.

Data were screened and trimmed on the basis of quality scores and bases below a quality threshold of 25 were discarded. Sequences with less than $250 \mathrm{nt}$ and chimeric sequences were removed using UCHIME (Dowd et al., 2008; Edgar et al., 2011). The open-source software QIIME was used to analyse the filtered sequences (Caporaso et al., 2010), which were clustered into operational taxonomic units (OTUs) at $97 \%$ sequence similarity using uclust (Edgar, 2010). RDP classifier was used to perform the taxonomic assignment down to the genus level, with a 0.8 bootstrap cut-off, the most abundant sequence of an OTU being considered representative (Cole et al., 2009). The Greengenes database (release gg_13_8_otus), included with the RDP classifier, was used for the taxonomic affiliations.

\section{Results and discussion}

\subsection{Electrochemical performance}

Four bioanodes and four OR biocathodes were formed separately under polarization at $+0.1 \mathrm{~V} / \mathrm{SCE}$. The current densities recorded at the end of this 12-day polarization phase are given in Table 1 . On this basis, 4 MFCs were designed by associating the bioanode and OR biocathode that produced the highest current densities, in decreasing order from MFC1 to MFC4.

The 4 MFCs produced power continuously through an external resistance of $1200 \Omega$. The power densities displayed during 13 days are presented in Fig. 2. During days 0 to 6 , the four MFCs displayed similar power density, around $40 \mathrm{~mW} \mathrm{~m} \mathrm{~m}^{-2}$, except MFC1, which suffered an incidental loss of oxygen supply during days 1 to 3 . After day 6 , a clear difference was observed between MFCs 1 and 2 on the one hand and MFCs 3 and 4 on the other. MFCs 1 and 2 displayed a rise in power production. MFC1 produced up to $238 \mathrm{~mW} \mathrm{~m}^{-2}$ on day 8.2 . On average, from day 7 to day 13, the power density produced was $209 \pm 24 \mathrm{~mW}$ $\mathrm{m}^{-2}$ and $143 \pm 13 \mathrm{~mW} \mathrm{~m}^{-2}$ for MFC1 and MFC2, respectively. In contrast, the power generated by MFCs 3 and 4 remained lower, continuously displaying around $40 \mathrm{~W} \mathrm{~m}^{-2}$ until the end of the experiment. These different behaviours matched the method chosen to design the MFCs, by associating the best performing bioanodes and best performing OR biocathodes in decreasing order from MFC1 to MFC4.

Power curves were recorded on days $0,3,6,9$ and 13 . The maximum power densities are reported in Table 1 . As expected from the record of the power density versus time, two different behaviours were observed, with MFC 1 and 2 on one side, and MFC 3 and 4 on the other. MFC 3 and 4 , which were equipped with the less well performing bioanodes and OR biocathodes, produced rather constant power density throughout their operation, with mean values of $57 \pm 19$ and $43 \pm 11 \mathrm{~mW} \mathrm{~m}^{-2}$, respectively. In contrast, the power density produced by MFCs 1 and 2 evolved over time. MFC1 produced from $64 \mathrm{~mW} \mathrm{~m}^{-2}$ on day 0 to 272 $\mathrm{mW} \mathrm{m} \mathrm{m}^{-2}$ on day 9 . Power densities recorded with MFC 2 increased along the experimental timescale from 66 to $201 \mathrm{~mW} \mathrm{~m}^{-2}$ on day 13 .

Power curves and polarization curves obtained with MFC1, the best performing MFC, are presented in Fig. 3. The initial (day 0) maximum power density of $64 \mathrm{~mW} \mathrm{~m}^{-2}$ was obtained with an external resistance $\mathrm{R}$ of $3300 \Omega$, while the maximum of $272 \mathrm{~mW} \mathrm{~m}^{-2}$ recorded at day 9 corresponded to $\mathrm{R}=1000 \Omega$ with a cell voltage of $585 \mathrm{mV}$. After day 0 , the maximum power density fell to lower values $\left(158 \mathrm{~mW} \mathrm{~m}^{-2}\right.$ at day

\section{Table 1}

Maximum current densities recorded with the four bioanodes $\left(\mathrm{J}_{\mathrm{an}}\right)$ and biocathodes $\left(\mathrm{J}_{\mathrm{cat}}\right)$ after twelve days of polarization at $+0.1 \mathrm{~V} / \mathrm{SCE}$ and maximal power densities $\left(\mathrm{P}_{\max }\right)$ recorded with the four MFCs after 0, 3, 6, 9 and 13 days of operation.

\begin{tabular}{llllllll}
\hline MFC & $\begin{array}{l}\mathrm{J}_{\mathrm{an}}(\mathrm{A} \\
\left.\mathrm{m}^{-2}\right)\end{array}$ & $\begin{array}{l}\mathrm{J}_{\text {cat }}(\mathrm{A} \\
\left.\mathrm{m}^{-2}\right)\end{array}$ & \multicolumn{5}{c}{ Maximal Power Density $\mathrm{P}_{\max }\left(\mathrm{mW} \mathrm{m}^{-2}\right)$} \\
\cline { 4 - 8 } & & t0 & 3 days & 6 days & 9 days & 13 days \\
\hline 1 & 5.04 & -0.53 & 64 & $15^{*}$ & 99 & 272 & 158 \\
2 & 3.92 & -0.47 & 66 & 71 & 72 & 127 & 201 \\
3 & 2.92 & -0.31 & 52 & 42 & 74 & 34 & 85 \\
4 & 1.88 & -0.10 & 48 & 32 & 44 & 32 & 59 \\
\hline
\end{tabular}

* power density lower than normally expected due to an incidental loss of oxygen supply in the catholyte. 


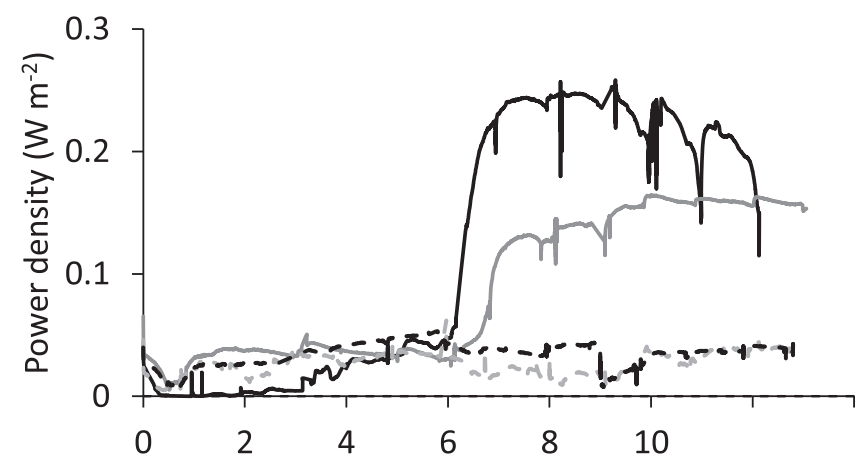

Fig. 2. Evolution of the power density $\left(\mathrm{W} \mathrm{m}^{-2}\right)$ displayed by the four MFCs during the thirteen days of operation. Plain black: MFC1; plain grey: MFC2; dashed black: MFC3; dashed grey: MFC4. Brutal changes on the curves observed on days $3,6,9$ and 13 correspond to the power curve records.

\section{3 for $\mathrm{R}=1000 \Omega$ ).}

Polarization curves of the bioanode and the OR biocathode of MFC1 are presented on Fig. 3B. Power and polarization curves observed on day 3 stood apart from the others obtained on days $0,6,9$ and 13, due to an incidental stop of the air supply to MFC1 between days 1 and 3. However, the performance of the fuel cell was soon restored when air supply to the cathodic compartment restarted, as reflected in curves recorded on days 6,9 and 13. This shows the robustness of the OR biocathodes and of the microbial catalyst. It also indicates the importance of the air supply to sustain the activity of the OR biocathode and, consequently, the main limitation due to oxygen transfer, already well-identified beyond the scope of hypersaline conditions (Milner and Yu, 2018).

The polarization curves revealed a high stability for the bioanode (Fig. 3B, black lines). From the measurements performed on day 3 to the measurements on day 13 , the bioanode current-potential curves changed little. In contrast, the biocathode current-potential curves (Fig. 3B, grey lines) evolved significantly. The biocathode produced higher current intensities in increasing order on days 6,12 , and 9, which corresponds to the same increasing order as the power densities produced by the MFC (Fig. 3A). The biocathode clearly controlled the performance of the MFC.

Moreover, the polarization curves also showed that the overpotentials at the biocathode were always considerably higher than those at the bioanode (Fig. 3B). The overpotentials can be evaluated from the polarization curves as the difference between the potential at zero current and the potential obtained when the MFC operated with a given value of the external resistance. The maximum value of the overpotential was measured when the MFC was run with the lowest resistance, here of $10 \Omega$. For the biocathode, the maximum overpotential was 682,608 and $613 \mathrm{mV}$ at days 6,9 and 12, respectively while, for the bioanode, it was only 76, 153 and $102 \mathrm{mV}$. The consistently higher values of the biocathode overpotential confirm that the biocathode was the rate-limiting element of the MFC.

Interestingly, the polarization curves on days 9 and 13 recalled the shapes of the voltammograms reported with similar OR biocathodes, also formed from salt marsh, in a previous study (Rimboud et al., 2021). Two distinctive redox systems were reported for oxygen reduction around -0.22 and $+0.20 \mathrm{~V} / \mathrm{SCE}$. The previous study investigated the OR biocathodes in analytical conditions only, i.e. in a 3-electrode system. Here, implementing similar OR biocathodes in MFCs, showed that the rise observed in MFC performance from day 9 was directly linked to the apparition of the redox system centred at $+0.20 \mathrm{~V} / \mathrm{SCE}$. Similarly, the redox system centred at $+0.20 \mathrm{~V} / \mathrm{SCE}$ also appeared at day 9 on the MFC2 biocathode, while it was absent for the biocathodes of MFC 3 and 4. Actually, it began to be discernible for MFC3 at the end of the experiment, at day 13.

The evolution of the potential displayed by the MFC1 bioanode and OR biocathode during operation are presented in Fig. 3C. As observed above with the polarization curves, the bioanode remained highly stable throughout the duration of the experiment, displaying a stable potential of $-0.42 \pm 0.02 \mathrm{~V} / \mathrm{SCE}$. An identical stability was observed with the other bioanodes of MFCs 2 to 4, with average potential values of $-0.43 \pm 0.01,-0.51 \pm 0.01$ and $-0.47 \pm 0.02 \mathrm{~V} / \mathrm{SCE}$, respectively.

The behaviour of the OR biocathode was clearly different (Fig. 3C). After day 6, the potential of the OR biocathode quickly rose from around $-0.20 \mathrm{~V} / \mathrm{SCE}$ to reach $+0.20 \mathrm{~V} / \mathrm{SCE}$ on day 7.5. It stabilized thereafter, at around $+0.17 \mathrm{~V} / \mathrm{SCE}$, until the end of the operation. This value of potential is in accordance with the voltammetry curves for oxygen reduction previously recorded with similar OR biocathodes (Rimboud et al., 2021).

To sum up, unsurprisingly with constant bioanode behaviour, the evolution of the power generated by MFCs 1 and 2 followed a pattern similar to the evolution of their OR biocathodes. The power increase observed at day 9 was correlated with the appearance of a redox system of oxygen reduction centred at $+0.20 \mathrm{~V} / \mathrm{SCE}$ on the biocathodes. Interestingly, this redox system also began to appear at day 13 on MFC3, which is encouraging information for the long-term evolution of these OR biocathodes and the related MFCs.

\subsection{Discussion of the electrochemical performance}

The average values of power density, which were sustained here for a week by MFC1 $\left(209 \pm 24 \mathrm{~mW} \mathrm{~m}^{-2}\right)$ and MFC2 $\left(143 \pm 13 \mathrm{~mW} \mathrm{~m}^{-2}\right)$, were around 3 times the maximum power density reported in the literature for a similar hypersaline MFC equipped with an OR microbial cathode, which was $65 \mathrm{~mW} \mathrm{~m}{ }^{-2}$ (Roustazadeh Sheikhyousefi et al., 2017). Beyond the context of hypersaline electrolytes, maximum power densities of $554 \mathrm{~mW} \mathrm{~m}^{-2}$ (Xia et al., 2013), $620 \mathrm{~mW} \mathrm{~m}^{-2}$ (Milner et al., 2016; Milner and Yu, 2018) and $679 \mathrm{~mW} \mathrm{~m}^{-2}$ (Wetser et al., 2015) have been reported for different MFC systems equipped with OR microbial cathodes.

On the one hand, it is encouraging to note that the performance obtained here was at the level of the highest reported in the literature for MFCs equipped with OR microbial cathodes. Nevertheless, on the other hand, it must be acknowledged that the highest power densities reported in the literature have been obtained with common electrolytes. The benefit of the hypersaline electrolyte used here is consequently not obvious. Actually, this remark is valid for all hypersaline MFCs. To date, the power densities reported for hypersaline MFCs do not exceed those of the MFCs using common electrolytes, while the hypersaline electrolytes should minimize the internal resistance of the system, which is a major sticking point in MFC development.

A simple calculation can help in assessing the impact of the ohmic drop on the MFC performance. From day 7 to day 13, MFC1, which produced the highest power, operated at an average cell voltage of around $0.6 \mathrm{~V}$ (Fig. 3C) with an external load of $1200 \Omega$. The current was consequently $0.5 \mathrm{~mA}$. According to Ohm's law applied to the electrolytes, the ohmic drop $(\Delta U)$ through the electrolyte is:

$\Delta U=R_{S} I$

where $R_{S}$ is the resistance of the solution between the anode and the cathode and $I$ is the current flowing through the electrolyte. $R_{S}$ can be calculated as:

$R_{S}=\rho \frac{l}{A}$

where $\rho$ is the resistivity of the solution $(\Omega \mathrm{m}), l$ is the distance between the anode and the cathode and $A$ is the cross-sectional area of the solution through which the ionic current flows. Here, $l$ was around $6 \mathrm{~cm}$ and A can be taken equal to the electrode area of $12.5 \mathrm{~cm}^{2}$. The electrolyte had an ionic conductivity of $10.4 \mathrm{~S} \mathrm{~m}^{-1}$, which means a resistivity $\rho$ of $0.1 \Omega \mathrm{m}$. The resistance of the electrolyte $R_{S}$ can thus be estimated at $4.8 \Omega$ (equation (3)) and the ohmic drop for a current of 

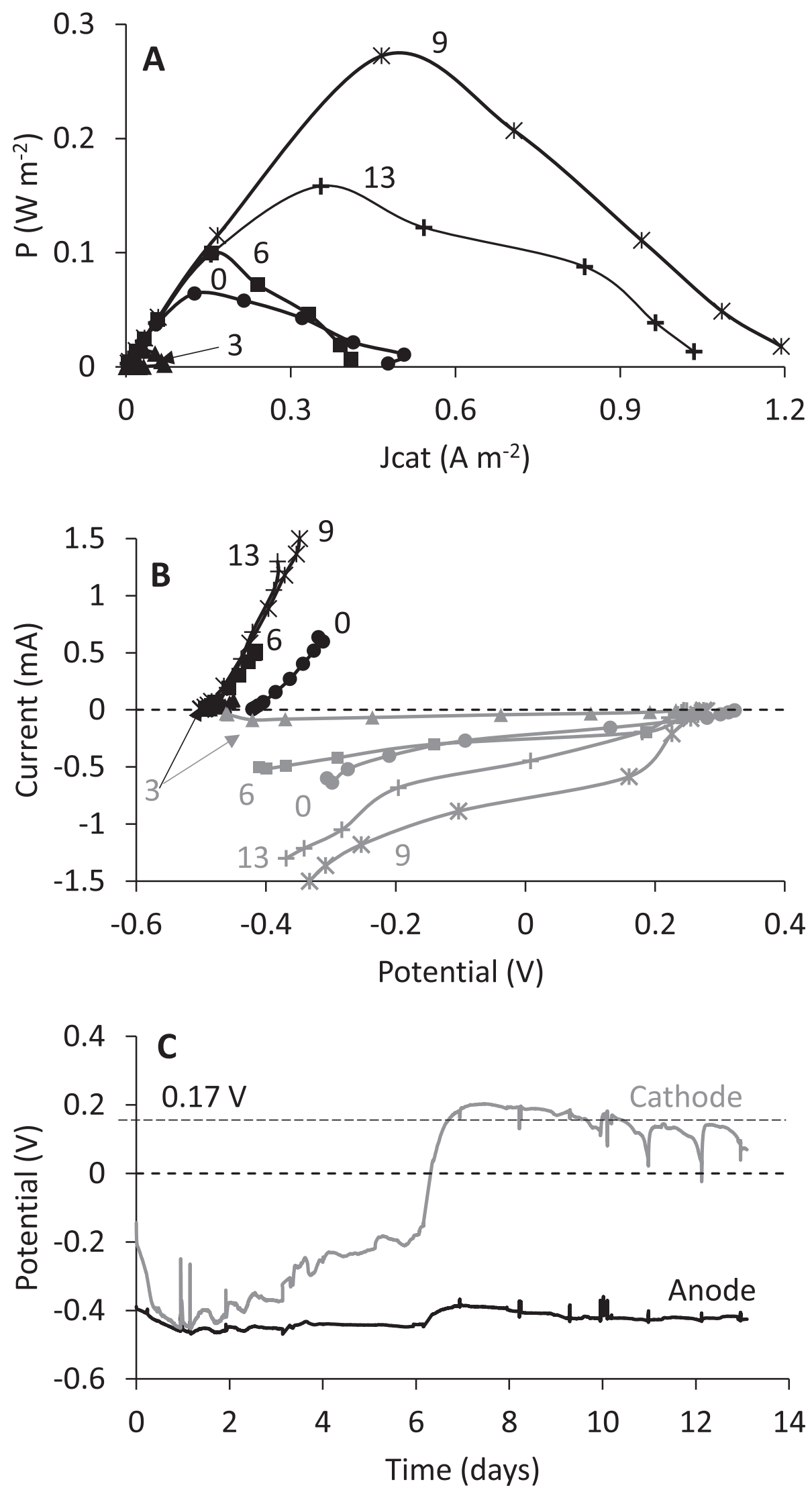

Fig. 3. (A) Power and (B) Polarization curves recorded with MFC1 at 3, 6, 9 and 13 days. Each curve is labelled with the time in days; curves recorded on day 3 are anomalous, due to a loss of the oxygen supply between days 1 and 3; (C) Evolution of the potential of the anode and cathode of MFC1. 
$0.5 \mathrm{~mA}$ at $2.4 \mathrm{mV}$ (equation (2)). The electrolyte fulfilled its mission perfectly: the small ohmic drop it induced can be neglected. Nevertheless, the same estimation for the type of electrolyte that is commonly used in MFCs, with an ionic conductivity around $1 \mathrm{~S} \mathrm{~m}^{-1}$, gives an ohmic drop of only $24 \mathrm{mV}$. Actually, the current is too low for the ohmic drop due to the electrolyte to be rate-limiting. The hypersaline electrolyte used here divided the ohmic drop by a factor of 10 with respect to usual MFC electrolytes but the current was too small for this benefit to be noticeable. It was observed here that the behaviour of the MFC was controlled by the performance of the OR biocathode, which was ratelimiting. The biocathode limited the MFC performance and, consequently, the current was not high enough for the interest of the high ionic conductivity of the electrolyte to be detected.

For instance, the same estimation made with a current of $15 \mathrm{~mA}$ gives an ohmic drop of $72 \mathrm{mV}$ with the hypersaline electrolyte, which is still acceptable, while $720 \mathrm{mV}$ would be reached with a usual electrolyte, which would preclude the production of any power.

Here, a first advance has been achieved by designing an OR microbial cathode that works in a hypersaline MFC and results in power density at the level of the highest values reported in the literature with common MFCs implementing OR microbial cathodes. For the future, the kinetics of the OR microbial cathode needs to be improved in order to take advantage of the hypersaline conditions in terms of minimized ohmic drop. One obvious way to improve the cathode kinetics is to implement an air-breathing configuration (Rago et al., 2017; 2018). Another way should be to promote the development of the redox system centred at $+0.20 \mathrm{~V} / \mathrm{SCE}$, which was observed to be linked with the improvement of the OR biocathode during MFC operation here.

\subsection{Microbial population analyses}

Gini-Simpson indexes for the anodic biofilms were in the range of 0.07 (MFC2) to 0.76 (MFC 4) (they were 0.42 and 0.67 for MFC1 and MFC3, respectively). The Gini-Simpson index represents the probability of interspecific encounter. If null, it indicates that only one genus is represented in the sample. An index of 0.07 for the anodic biofilm in MFC2 clearly indicates the high dominance of one genus (Desulfuromonas, see below).

The Gini-Simpson indexes of the cathodic biofilms were slightly higher, in the range of 0.73 (MFC4) to 0.91 (MFC1) (they were 0.86 and 0.88 for MFC2 and MFC3, respectively). As stated in previous observations (Rimboud et al., 2015, 2017), microbial populations of cathodic biofilms tend to be more diverse and less dominated (mean GiniSimpson of 1.77) than those in anodic biofilms (mean Gini-Simpson of 1.06).

The most represented bacterial orders encountered in the anodic and cathodic biofilms can be seen in Fig. 4. The most represented genera (when identifiable) are numbered in Table 2 (2A: anodic biofilms; 2B: cathodic biofilms). The phylum Proteobacteria was the most represented in all biofilms, though differences between anodic and cathodic biofilms appeared at the class level. Anodic biofilms were clearly dominated by bacteria from the class Deltaproteobacteria, with a lower presence of Gammaproteobacteria. Cathodic biofilms were dominated by a variable mix of Alpha- and Gammaproteobacteria, with a characteristic absence of Deltaproteobacteria (mostly anaerobic).

In the anodic biofilms, the order Desulfuromonadales was largely dominant, in proportions from $38.2 \%$ for MFC4 up to $96.3 \%$ for MFC2. A single genus, Desulfuromonas, accounted for this dominance (Table 2A). Bacteria from order Desulfurobacterales (deltaproteobacteria) were also found at $23.6 \%$ on the MFC4 anode. Gammaproteobacteria were represented by bacteria from the Oceanospirillales order, in majority by the Marinobacterium genus (Table 2A).

The Rhodobacterales order (Alphaproteobacteria) was the most represented inside cathodic biofilms (from $35.2 \%$ on MFC 1 to $74.1 \%$ on MFC 4). At genus level, however, high dispersion was observed, with several genera of the Roseobacter clade (Roseovarius, Lutimaribacter,
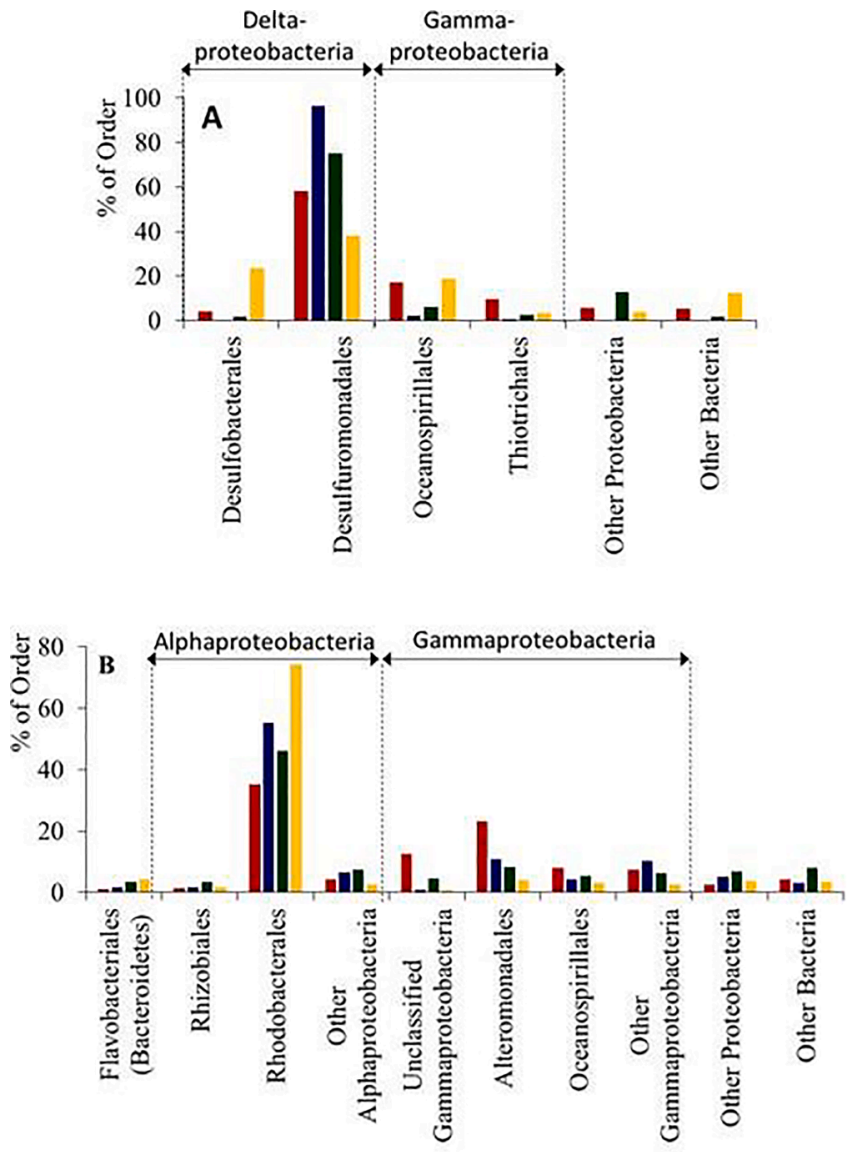

Fig. 4. Microbial communities at order level displayed in the electroactive biofilms of the four MFCs. (A) anodic communities; (B) cathodic communities.

Labrenzia, etc.) accounting for the high proportion of Rhodobacterales (Table 2B). Gammaproteobacteria were represented by the orders Alteromonadales $(4.1 \%$ on MFC 4 to $23.3 \%$ on MFC 1 ) and Oceanospirillales (3.1\% on MFC 4 to $7.1 \%$ on MFC 1 ). Genera Marinobacter and Idiomarina were identified at genus level among Alteromonadales, and Marinobacterium genus among Oceanospirillales (Table 2B). Bacteria related to an unclassified order of Gammaproteobacteria already detected in high proportions on efficient OR biocathodes designed under polarization (Rimboud et al., 2021) were detected in proportions from $0.8 \%$ (MFC 4) to $12.5 \%$ (MFC 1 ).

\subsection{Discussion of the microbial populations}

With regard to the bioanodes, Desulfuromonas sp. was found in a surprisingly high proportion for the four MFCs. This genus belongs to the same order (Desulfuromonadales) as the well-known anode respiring Geobacter sp. Miyahara et al. demonstrated that the increasing salinity of the medium led to the preferential selection of Desulfuromonas instead of Geobacter in electroactive biofilms (Miyahara et al., 2016). Desulfuromonas was previously found among the dominant genera inside electroactive biofilms formed from salt marsh sediment (from 5.0 to $45.0 \%$ ) (Rousseau et al., 2014; 2016), but not in such abundance as observed here. In the studies of Rousseau et al., Desulfuromonas sp. was found to be co-dominant in association with Marinobacter sp. in the anodic biofilms of a hydrogen-producing microbial electrolysis cell, which was formed from similar salt marsh sediment. The Marinobacter genus, however, was not detected here. A possible explanation for the lack of Marinobacter sp. in the anodic biofilms may be the use of a well-sealed anodic compartment. As Marinobacter sp. is mostly aerobic, it may have benefitted from a low diffusion of oxygen in the set-up used in the 
Table 2

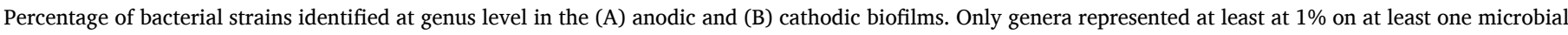
electrode are presented.

\begin{tabular}{|c|c|c|c|c|c|c|c|c|}
\hline & & & & & \multicolumn{4}{|c|}{ MFC } \\
\hline \multicolumn{5}{|c|}{ A: Anodic biofilms } & 1 & 2 & 3 & 4 \\
\hline Proteobacteria & Deltaproteobacteria & Desulfobacterales & Desulfobacteraceae & Desulfobacter & 3.9 & 0.3 & 1.8 & 23.1 \\
\hline Proteobacteria & Deltaproteobacteria & Desulfuromonadales & Desulfuromonadaceae & Desulfuromonas & 53.3 & 96.3 & 75.0 & 37.7 \\
\hline Proteobacteria & Deltaproteobacteria & Desulfuromonadales & Pelobacteraceae & Malonomonas & 1.7 & 0.0 & 0.0 & 0.2 \\
\hline Proteobacteria & Gammaproteobacteria & Oceanospirillales & Oceanospirillaceae & Marinobacterium & 17.1 & 2.2 & 6.1 & 18.6 \\
\hline Proteobacteria & Gammaproteobacteria & Thiotrichales & Piscirickettsiaceae & Thiomicrospira & 9.5 & 0.8 & 2.5 & 3.3 \\
\hline \multicolumn{5}{|c|}{ B: Cathodic biofilms } & & & & \\
\hline Bacteroidetes & Flavobacteriia & Flavobacteriales & Flavobacteriaceae & Flavirhabdus & 0.4 & 0.3 & 1.3 & 1.5 \\
\hline Proteobacteria & Alphaproteobacteria & Rhizobiales & Hyphomicrobiaceae & Robiginosimarina & 0.7 & 0.5 & 0.9 & 1.1 \\
\hline Proteobacteria & Alphaproteobacteria & Rhodobacterales & Rhodobacteraceae & Labrenzia & 0.4 & 0.8 & 1.8 & 0.1 \\
\hline Proteobacteria & Alphaproteobacteria & Rhodobacterales & Rhodobacteraceae & Leisingera & 1.1 & 0.6 & 1.5 & 1.8 \\
\hline Proteobacteria & Alphaproteobacteria & Rhodobacterales & Rhodobacteraceae & Lutimaribacter & 4.5 & 18.3 & 9.2 & 16.2 \\
\hline Proteobacteria & Alphaproteobacteria & Rhodobacterales & Rhodobacteraceae & Mameliella & 1.4 & 0.4 & 1.0 & 0.7 \\
\hline Proteobacteria & Alphaproteobacteria & Rhodobacterales & Rhodobacteraceae & Pelagibaca & 2.1 & 0.3 & 1.4 & 0.9 \\
\hline Proteobacteria & Alphaproteobacteria & Rhodobacterales & Rhodobacteraceae & Pelagicola & 1.7 & 2.5 & 5.1 & 4.9 \\
\hline Proteobacteria & Alphaproteobacteria & Rhodobacterales & Rhodobacteraceae & Phaeobacter & 1.6 & 3.1 & 2.6 & 1.5 \\
\hline Proteobacteria & Alphaproteobacteria & Rhodobacterales & Rhodobacteraceae & Roseovarius & 17.7 & 21.2 & 20.7 & 37.1 \\
\hline Proteobacteria & Gammaproteobacteria & Alteromonadales & Alteromonadaceae & Marinobacter & 2.5 & 2.2 & 5.4 & 1.9 \\
\hline Proteobacteria & Gammaproteobacteria & Alteromonadales & Idiomarinaceae & Idiomarina & 3.4 & 1.5 & 0.3 & 1.3 \\
\hline Proteobacteria & Gammaproteobacteria & Cellvibrionales & Halieaceae & Haliea & 17.5 & 6.3 & 1.3 & 1.4 \\
\hline Proteobacteria & Gammaproteobacteria & Oceanospirillales & Alcanivoracaceae & Alcanivorax & 0.4 & 3.2 & 0.6 & 1.5 \\
\hline Proteobacteria & Gammaproteobacteria & Oceanospirillales & Alcanivoracaceae & Kangiella & 0.4 & 1.1 & 0.3 & 1.2 \\
\hline Proteobacteria & Gammaproteobacteria & Oceanospirillales & Halomonadaceae & Halomonas & 2.4 & 2.1 & 0.2 & 0.3 \\
\hline Proteobacteria & Gammaproteobacteria & Oceanospirillales & Oceanospirillaceae & Marinobacterium & 8.8 & 1.1 & 4.8 & 1.4 \\
\hline Proteobacteria & Gammaproteobacteria & Thiotrichales & Piscirickettsiaceae & Methylophaga & 1.3 & 0.7 & 0.7 & 0.3 \\
\hline Proteobacteria & Gammaproteobacteria & Unclassified* & Unclassified* & Unclassified* & 12.5 & 0.9 & 4.7 & 0.8 \\
\hline
\end{tabular}

* the proportions of the unclassified Gammaproteobacteria, though not taxonomically identified to the genus level, are presented for comparison.

previous studies, which were not perfectly airtight. On the other hand, with a well-sealed set-up, the development of the strictly anaerobic Desulfuromonas sp. would have been favoured, which can explain the higher proportion of this genus observed here.

To sum up, in the anodic biofilms, the high abundance of Desulfuromonas sp. confirms the key role of these species, as already speculated for similar hypersaline bioanodes formed from salt marsh sediment. However, Desulfuromonas sp. has always been found in association with Marinobacter sp. so far. The absence of the latter species here very strongly reinforces the probability that Desulfuromonas $s p$. is the key electroactive species responsible for the high current density produced by hypersaline bioanodes.

The biofilms of the biocathodes were dominated by bacteria from the class Alphaproteobacteria, especially by bacteria from the Roseovarius clade of the Rhodobacteraceae family. This was observed in our previous work (Rimboud et al., 2021) and two main and additional reasons may explain this dominance: i) the known ability of these bacteria to form biofilms rapidly (primo-adhesion) (Dang et al., 2008; Elifantz et al., 2013); ii) the implication of these bacteria in the bio-geochemical cycle of sulfur, which enables them to thrive in media poor in organic matter (Luo and Moran, 2014; Tang et al., 2016).

In our previous work, similar OR biocathodes were formed from salt marsh under constant polarization in 3-electrode analytical set-ups, without being coupled with bioanodes to operate in MFC configuration (Rimboud et al., 2021). In this previous study, bacteria from an unclassified order of Gammaproteobacteria, phylogenetically linked to the genus Thioalobacter, were found in great abundance ( 5 to $52.6 \%$ ) and the biocathodes produced stable current density in the 0.25 to $0.91 \mathrm{~A}$ $\mathrm{m}^{-2}$ range under constant applied potential of $0.1 \mathrm{~V} / \mathrm{SCE}$. In the present work, these bacteria were only detected in a significant amount (12.5\%) on the OR biocathode of the best-performing MFC (MFC1). The polarization curves (Fig. 3B) show that this biocathode produced the maximum current intensity at day 9 , with a current intensity of around $-0.75 \mathrm{~mA}$ at $0.1 \mathrm{~V} / \mathrm{SCE}$, i.e. a current density of around $0.60 \mathrm{~A} \mathrm{~m}^{-2}$, which was consistent with the values previously reported. This confirms the previously speculated importance of these bacteria in the design of efficient hypersaline OR biocathodes.

These unclassified Gammaproteobacteria probably need a long time under polarization to develop fully. Their low representation in the less performing bioanodes of the present study, in comparison to the previous study, can be explained by the shorter duration of the polarization phase at $+0.1 \mathrm{~V} / \mathrm{SCE}$ (12 days) compared to the previous study (21 days) (Rimboud et al., 2021). Actually, at the end of the 12-day formation phase at $+0.1 \mathrm{~V} / \mathrm{SCE}$, when the biocathodes were coupled to the bioanodes, their potential was immediately pulled by the bioanode towards lower values, about $-0.4 \mathrm{~V} / \mathrm{SCE}$ (Fig. 3C). It then took about a week for the potential of the biocathode to recover a value around $+0.1 \mathrm{~V} / \mathrm{SCE}$.

Similarly, the lower proportion of the other Gammaproteobacteria (Alteromonadales and Oceanospirillales) compared to the Alphaproteobacteria can be explained by the shorter duration of the polarization phase and the tactical advantages of the Rhodobacteraceae's ability to assemble quickly in biofilms. Several studies have pointed toward the high presence of Gammaproteobacteria in highly active OR biocathodes 
(Rimboud et al., 2021; Milner et al., 2016; Desmond-Le Quemener et al., 2016; Rothballer et al., 2015; Strycharz-Glaven et al., 2013). Their low presence here in the biofilms, compared to the Alphaproteobacteria, may be an explanation of the lower activity of OR biocathodes in MFCs 3 and 4.

To sum up, the efficiency of the OR biocathodes seems to be linked to the presence of an unclassified order of Gammaproteobacteria, phylogenetically linked to the genus Thioalobacter. The OR bioanodes previously reported were formed in similar operating conditions but with a longer period of applied potential. They showed higher proportions of the same unclassified order of Gammaproteobacteria and produced higher current densities. The comparison with the results obtained here supports the hypothesis that increasing the abundance of this species should be the way to improve the efficiency of the OR biocathodes, and that this could be done by extending the time of the biocathode formation phase at $+0.1 \mathrm{~V} / \mathrm{SCE}$. Practically, this could be achieved either by extending the time under polarization before coupling anode and cathode, or by adjusting the value of the external resistance of the MFC in order to keep a high cell voltage (i.e. high resistance value) during the early days of MFC operation.

\section{Conclusion}

For the first time, it has been shown that hypersaline MFCs equipped with OR microbial cathodes can produce power densities at the level of the highest performance reported so far for MFCs working with OR biocathodes. Desulfuromonas $s p$. were confirmed to be key species of the hypersaline bioanodes. The efficiency of the OR biocathodes was linked to the presence of Gammaproteobacteria (Alteromonadales and Oceanospirillales) and, especially, an unclassified order phylogenetically linked to the genus Thioalobacter. The development of these species may be favoured by maintaining polarization at $+0.1 \mathrm{~V} / \mathrm{SCE}$ over a long period, typically more than 12 days.

\section{CRediT authorship contribution statement}

Mickaël Rimboud: Conceptualization, Methodology, Investigation, Writing - original draft, Writing - review \& editing. Luc Etcheverry: . Mohamed Barakat: Validation, Investigation. Wafa Achouak: Validation, Writing - review \& editing, Supervision. Alain Bergel: Conceptualization, Writing - original draft, Writing - review \& editing. MarieLine Délia: Conceptualization, Methodology, Validation, Investigation, Supervision, Project administration.

\section{Declaration of Competing Interest}

The authors declare that they have no known competing financial interests or personal relationships that could have appeared to influence the work reported in this paper.

\section{Acknowledgments}

This work was supported by funding from the French state, managed by the Agence Nationale de la Recherche (ANR), within the framework of the Koropokkuru project (ANR-14-CE05-0004).

\section{References}

Abrevaya, X.C., Sacco, N., Mauas, P.J.D., Cortón, E., 2011. Archaea-based microbial fuel cell operating at high ionic strength conditions. Extremophiles 15 (6), 633-642. https://doi.org/10.1007/s00792-011-0394-z.

Caporaso, J.G., Kuczynski, J., Stombaugh, J., Bittinger, K., Bushman, F.D., Costello, E.K., Fierer, N., Peña, A.G., Goodrich, J.K., Gordon, J.I., Huttley, G.A., Kelley, S.T., Knights, D., Koenig, J.E., Ley, R.E., Lozupone, C.A., McDonald, D., Muegge, B.D., Pirrung, M., Reeder, J., Sevinsky, J.R., Turnbaugh, P.J., Walters, W.A., Widmann, J., Yatsunenko, T., Zaneveld, J., Knight, R., 2010. QIIME allows analysis of highthroughput community sequencing data. Nat. Methods 7 (5), 335-336. https://doi. org/10.1038/nmeth.f.303.
Cole, J.R., Wang, Q., Cardenas, E., Fish, J., Chai, B., Farris, R.J., Kulam-Syed-

Mohideen, A.S., McGarrell, D.M., Marsh, T., Garrity, G.M., Tiedje, J.M., 2009. The ribosomal database project: Improved alignments and new tools for rRNA analysis. Nucleic Acids Res. 37 (Database), D141-D145. https://doi.org/10.1093/nar/ gkn879.

Dang, H., Li, T., Chen, M., Huang, G., 2008. Cross-ocean distribution of Rhodobacterales bacteria as primary surface colonizers in temperate coastal marine waters. Appl. Environ. Microbiol. 74 (1), 52-60. https://doi.org/10.1128/AEM.01400-07.

Desmond-Le Quemener, E., Rimboud, M., Bridier, A., Madigou, C., Erable, B., Bergel, A., Bouchez, T., 2016. Biocathodes reducing oxygen at high potential select biofilms dominated by Ectothiorhodospiraceae populations harboring a specific association of genes. Bioresour. Technol. 214, 55-62. https://doi.org/10.1016/j. biortech.2016.04.087.

Dowd, S.E., Callaway, T.R., Wolcott, R.D., Sun, Y., McKeehan, T., Hagevoort, R.G., Edrington, T.S., 2008. Evaluation of the bacterial diversity in the feces of cattle using 16S rDNA bacterial tag-encoded FLX amplicon pyrosequencing (bTEFAP). BMC Microbiol. 8 (1), 125. https://doi.org/10.1186/1471-2180-8-125.

Edgar, R.C., 2010. Search and clustering orders of magnitude faster than BLAST. Bioinformatics 26, 2460-2461. https://doi.org/10.1093/bioinformatics/btq461.

Edgar, R.C., Haas, B.J., Clemente, J.C., Quince, C., Knight, R., 2011. UCHIME improves sensitivity and speed of chimera detection. Bioinformatics 27, 2194-2200.

Elifantz, H., Horn, G., Ayon, M., Cohen, Y., Minz, D., 2013. Rhodobacteraceae are the key members of the microbial community of the initial biofilm formed in Eastern Mediterranean coastal seawater. FEMS Microbiol. Ecol. 85 (2), 348-357. https://doi. org/10.1111/1574-6941.12122.

Erable, B., Féron, D., Bergel, A., 2012. Microbial catalysis of the oxygen reduction reaction for microbial fuel cells: A review. Chem. Sus. Chem. 5 (6), 975-987. https:// doi.org/10.1002/cssc.201100836.

Grattieri, M., Minteer, S.D., 2018. Microbial fuel cells in saline and hypersaline environments: Advancements, challenges and future perspectives. Bioelectrochemistry 120, 127-137. https://doi.org/10.1016/j. bioelechem.2017.12.004.

Grattieri, M., Shivel, N.D., Sifat, I., Bestetti, M., Minteer, S.D., 2017a. Sustainable hypersaline microbial fuel cells: Inexpensive recyclable polymer supports for carbon nanotube conductive paint anodes. Chem. Sus. Chem. 10 (9), 2053-2058. https:// doi.org/10.1002/cssc.201700099.

Grattieri, M., Suvira, M., Hasan, K., Minteer, S.D., 2017b. Halotolerant extremophile bacteria from the Great Salt Lake for recycling pollutants in microbial fuel cells. J. Power Sources 356, 310-318. https://doi.org/10.1016/j.jpowsour.2016.11.090.

Huang, L., Regan, J.M., Quan, X., 2011. Electron transfer mechanisms, new applications, and performance of biocathode microbial fuel cells. Bioresour. Technol. 102, 316-323. https://doi.org/10.1016/j.biortech.2010.06.096.

Liew, K.B., Daud, W.R.W., Ghasemi, M., Leong, J.X., Lim, S.S., Ismail, M., 2014. Non-Pt catalyst as oxygen reduction reaction in microbial fuel cells: A review. Int. J. Hydrog. Energy 39, 4870-4883. https://doi.org/10.1016/j.ijhydene.2014.01.062.

Luo, H., Moran, M.A., 2014. Evolutionary ecology of the marine Roseobacter clade. Microbiol. Mol. Biol. Rev. MMBR 78 (4), 573-587. https://doi.org/10.1128/ MMBR.00020-14.

Milner, E.M., Popescu, D., Curtis, T., Head, I.M., Scott, K., Yu, E.H., 2016. Microbial fuel cells with highly active aerobic biocathodes. J. Power Sources 324, 8-16. https:// doi.org/10.1016/j.jpowsour.2016.05.055.

Milner, E.M., Yu, E.H., 2018. The effect of oxygen mass transfer on aerobic biocathode performance, biofilm growth and distribution in microbial fuel cells. Fuel Cells 18 (1), 4-12. https://doi.org/10.1002/fuce:201700172.

Miyahara, M., Kouzuma, A., Watanabe, K., 2016. Sodium chloride concentration determines exoelectrogens in anode biofilms occurring from mangrove-grown brackish sediment. Bioresour. Technol. 218, 674-679. https://doi.org/10.1016/j. biortech.2016.07.015.

Miyahara, M., Kouzuma, A., Watanabe, K., 2015. Effects of $\mathrm{NaCl}$ concentration on anode microbes in microbial fuel cells. AMB Express 5, 123. https://doi.org/10.1186/ s13568-015-0123-6.

Nam, J.-Y., Logan, B.E., 2011. Enhanced hydrogen generation using a saline catholyte in a two chamber microbial electrolysis cell. Int. J. Hydrog. Energy 36 (23), 15105-15110. https://doi.org/10.1016/j.ijhydene.2011.08.106.

Oliot, M., Etcheverry, L., Bergel, A., 2016a. Removable air-cathode to overcome cathode biofouling in microbial fuel cells. Bioresour. Technol. 221, 691-696. https://doi. org/10.1016/j.biortech.2016.09.095.

Oliot, M., Galier, S., Roux de Balmann, H., Bergel, A., 2016b. Ion transport in microbial fuel cells: Key roles, theory and critical review. Appl. Energy 183, 1682-1704. https://doi.org/10.1016/j.apenergy.2016.09.043.

Pasternak, G., Greenman, J., Ieropoulos, I., 2016. Regeneration of the power performance of cathodes affected by biofouling. Appl. Energy 173, 431-437. https:// doi.org/10.1016/j.apenergy.2016.04.009.

Rago, L., Cristiani, P., Villa, F., Zecchin, S., Colombo, A., Cavalca, L., Schievano, A., 2017. Influences of dissolved oxygen concentration on biocathodic microbial communities in microbial fuel cells. Bioelectrochemistry 116, 39-51. https://doi. org/10.1016/j.bioelechem.2017.04.001.

Rago, L., Zecchin, S., Marzorati, S., Goglio, A., Cavalca, L., Cristiani, P., Schievano, A., 2018. A study of microbial communities on terracotta separator and on biocathode of air breathing microbial fuel cells. Bioelectrochemistry 120, 18-26. https://doi. org/10.1016/j.bioelechem.2017.11.005.

Rimboud, M., Barakat, M., Achouak, W., Bergel, A., Délia, M.-L., 2021. Oxygen-reducing microbial cathodes in hypersaline electrolyte. Bioresour. Technol. 319, 124165. https://doi.org/10.1016/j.biortech.2020.124165.

Rimboud, M., Barakat, M., Bergel, A., Erable, B., 2017. Different methods used to form oxygen reducing biocathodes lead to different biomass quantities, bacterial 
communities, and electrochemical kinetics. Bioelectrochemistry 116, 24-32. https:// doi.org/10.1016/j.bioelechem.2017.03.001.

Rimboud, M., Desmond-Le Quemener, E., Erable, B., Bouchez, T., Bergel, A., 2015. The current provided by oxygen-reducing microbial cathodes is related to the composition of their bacterial community. Bioelectrochemistry 102, 42-49. https:// doi.org/10.1016/j.bioelechem.2014.11.006.

Robertson, S.J., Grattieri, M., Behring, J., Bestetti, M., Minteer, S.D., 2019. Transitioning from batch to flow hypersaline microbial fuel cells. Electrochim. Acta 317, 494-501. https://doi.org/10.1016/j.electacta.2019.06.005.

Rothballer, M., Picot, M., Sieper, T., Arends, J.B.A., Schmid, M., Hartmann, A., Boon, N., Buisman, C.J.N., Barriere, F., Strik, D.P.B.T.B., 2015. Monophyletic group of unclassified gamma-Proteobacteria dominates in mixed culture biofilm of highperforming oxygen reducing biocathode. Bioelectrochemistry 106, 167-176. https://doi.org/10.1016/j.bioelechem.2015.04.004.

Rousseau, R., Dominguez-Benetton, X., Delia, M.-L., Bergel, A., 2013. Microbial bioanodes with high salinity tolerance for microbial fuel cells and microbial electrolysis cells. Electrochem. Commun. 33, 1-4. https://doi.org/10.1016/j. elecom.2013.04.002.

Rousseau, R., Ketep, S.F., Etcheverry, L., Délia, M.-L., Bergel, A., 2020. Microbial electrolysis cell (MEC): A step ahead towards hydrogen-evolving cathode operated at high current density. Bioresour. Technol. Rep. 9, 100399. https://doi.org/10.1016/j. biteb.2020.100399.

Rousseau, R., Rimboud, M., Delia, M.-L., Bergel, A., Basseguy, R., 2015. Electrochemical characterization of microbial bioanodes formed on a collector/electrode system in a highly saline electrolyte. Bioelectrochemistry 106, 97-104. https://doi.org/ 10.1016/j.bioelechem.2015.06.011.

Rousseau, R., Santaella, C., Achouak, W., Godon, J.-J., Bonnafous, A., Bergel, A., Délia, M.-L., 2014. Correlation of the electrochemical kinetics of high-salinitytolerant bioanodes with the structure and microbial composition of the biofilm. ChemElectroChem 1 (11), 1966-1975. https://doi.org/10.1002/celc.201402153.

Rousseau, R., Santaella, C., Bonnafous, A., Achouak, W., Godon, J.-J., Delia, M.-L. Bergel, A., 2016. Halotolerant bioanodes: The applied potantial modulates the electrochemical characteristics, the biofilm structure and the ration of the two dominant genera. Bioelectrochemistry 112, 24-32. https://doi.org/10.1016/j.

bioelechem.2016.06.006

Roustazadeh Sheikhyousefi, P., Nasr Esfahany, M., Colombo, A., Franzetti, A., Trasatti, S. P., Cristiani, P., 2017. Investigation of different configurations of microbial fuel cells for the treatment of oilfield produced water. Appl. Energy 192, 457-465. https:// doi.org/10.1016/j.apenergy.2016.10.057.

Santoro, C., Arbizzani, C., Erable, B., Ieropoulos, I., 2017. Microbial fuel cells: From fundamentals to applications. A review. J. Power Sources 356, 225-244. https://doi. org/10.1016/j.jpowsour.2017.03.109.

Santoro, C., Lei, Y., Li, B., Cristiani, P., 2012. Power generation from wastewater using single chamber microbial fuel cells (MFCs) with platinum-free cathodes and precolonized anodes. Biochem. Eng. J. 62, 8-16. https://doi.org/10.1016/j. bej.2011.12.006.

Strycharz-Glaven, S.M., Glaven, R.H., Wang, Z., Zhou, J., Vora, G.J., Tender, L.M., 2013. Electrochemical investigation of a microbial solar cell reveals a nonphotosynthetic biocathode catalyst. Appl. Environ. Microbiol. 79 (13), 3933-3942. https://doi.org/ 10.1128/AEM.00431-13.

Sun, H.-L., 2012. Electricity generation from seafood wastewater in a single- and dualchamber microbial fuel cell with CoTMPP oxygen-reduction electrocatalyst. J. Chem. Technol. Biotechnol. 87, 1167-1172. https://doi.org/10.1002/jctb.3741.

Tang, K., Yang, Y., Lin, D., Li, S., Zhou, W., Han, Y., Liu, K., Jiao, N., 2016. Genomic, physiologic, and proteomic insights into metabolic versatility in Roseobacter clade bacteria isolated from deep-sea water. Sci. Rep. 6, 35528.

Wei, J., Liang, P., Huang, X., 2011. Recent progress in electrodes for microbial fuel cells. Bioresour. Technol. 102, 9335-9344. https://doi.org/10.1016/j. biortech.2011.07.019.

Wetser, K., Sudirjo, E., Buisman, C.J.N., Strik, D.P.B.T.B., 2015. Electricity generation by a plant microbial fuel cell with an integrated oxygen reducing biocathode. Appl. Energy 137, 151-157. https://doi.org/10.1016/j.apenergy.2014.10.006.

Xia, X., Tokash, J.C., Zhang, F., Liang, P., Huang, X., Logan, B.E., 2013. Oxygen-reducing biocathodes operating with passive oxygen transfer in microbial fuel cells. Environ. Sci. Technol. 47 (4), 2085-2091. https://doi.org/10.1021/es3027659. 